\section{Planning of Industry and Labour Supply}

$\mathrm{T}$ $\mathrm{HE}$ reports of the investigations into the industrial conditions in certain economically depressed areas of the north of England, South Wales and Scotland* afford an impressive piece of evidence of the necessity for industrial planning on national lines if untoward social consequences are to be avoided. The picture of Durham and Tyneside, where whole areas have been drained of vitality, with the production of an attitude of resignation and of an incapacity to return to work when opportunity offers, through sheer lack of confidence and vitality, is appalling. Even this, and the urgent necessity of arresting the present decline, cannot overshadow Mr. J. C. C. Davidson's significant remarks on the need for a continuous survey of the problems of the depressed areas, and his endorsement of the recommendations of surveys recently made by the University of Liverpool that the State should devote greater resources to continuous intensive regional research, and play a greater part in regulating the initial location of new industries or businesses. His further conclusion that the worst problems in West Cumberland cannot be treated in isolation, but that the district must be treated as a whole, is in keeping with the conclusions reached by Sir Arthur Rose for Scotland and Sir Wyndham Portal for South Wales. All four commissioners, in fact, are at pains to emphasise the necessity for a national policy in regard to industrial transference and the development of new industries.

The report on West Cumberland indicates that this area is likely to have, for years to come, a substantial surplus of labour with no hope of outlet locally. There is little prospect of attracting new manufacturing industries, but on the other hand agriculture appears to offer greater possibilities than in the other areas, and afforestation also offers scope for development.

The need for a national policy is brought out very clearly by Capt. D. Euan Wallace in his report on Durham and Tyneside. He urges that steps be taken towards the national planning of industry, and recommends the unification of coalmining royalties, the formation of an Industrial Development Company for Tyneside and a land settlement scheme financed by the Exchequer, as well as the clearance of derelict sites. Similarly,

* Ministry of Labour. Reports of Investigations into the Industrial Conditions in Certain Depressed Areas of (1) West Cumberland and Haltwhistle, (2) Durham and Tyneside, (3) South Wales and Monmouthshire, (4) Scotland. (Cmd. 4728.) Pp. 240. (London: H.M. Stationery Office, 1934.) 38. 6d. net.
Sir Wyndham Portal directs attention to the danger of the situation in South Wales, which is practically dependent on the coal trade alone, being repeated in other parts of the country which rely on a single industry. If the economic planning of factories is not accompanied by the economic planning of labour supply, distressed areas may spring up in other places; planning of industry involves the simultaneous planning of labour supply. Already dangerous tendencies exist in the starting of steel and tinplate industries in Lincolnshire. The chief hope of industrial development in South Wales appears to be in the adoption of more scientific methods of utilising coal, and special reference is made to the possibility of the hydrogenation of coal being undertaken in South Wales. Pembroke, moreover, has outstanding claims for Government controlled works, and special stress is laid on the recommendation that some such factory should be located in the South Wales area.

The report on Scotland indicates that the problem there is not strictly one of derelict areas. There is evidence of definite surpluses of labour in the shalefields, North Ayrshire and Lanarkshire. The conditions in the whole area are mainly due to world conditions, and the removal of hindrances to international trade would go far to remedy matters. The tendency for industry to move south has deprived Scotland of the advantages of the new industrial developments, and it is considered that a designed direction of Government orders in rather larger proportions to the Clyde area would alleviate in a remarkably wide degree, and out of proportion to what it would do in other areas, the widespread and severe conditions of depression.

All of the commissioners allude to the growing volume of juvenile unemployment through the increasing number of 'school-leavers', and emphasise the importance of strenuous efforts at transfer. None of the reports, however, discusses the absorption capacity of other districts for this surplus, and Capt. Wallace is alone in referring to the effect on juvenile unemployment of raising the school leaving age, in spite of the close relation of this step to that of juvenile unemploy. ment in Great Britain as a whole. The reports are thus silent on one of the most critical and serious problems of the whole country - the prevention of the development of a hard core of juvenile unemployables, who have never known regular occupation, or at most, known it only for a year or two before displacement by fresh school-leavers. 